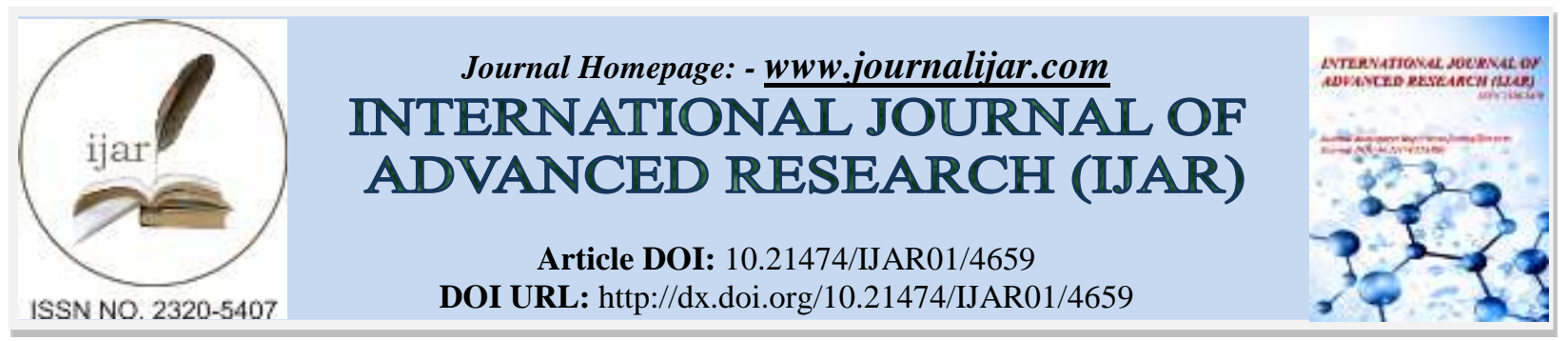

RESEARCH ARTICLE

\title{
DIET \& NUTRITION: CONCEPTUAL IMPORTANCE IN THE SPECIALITY OF ORTHODONTICS-A REVIEW.
}

Arya Ashish, Raghav Pradeep, Sharma Utkarsh and Kochhar Abhimanyu.

\section{Manuscript Info}

Manuscript History

Received: 25 April 2017

Final Accepted: 28 May 2017

Published: June 2017

\section{Abstract}

\section{Introduction:-}

In recent years people have become more aware and concerned about maintaining good health and having a healthy lifestyle. A good diet plays an important role in maintaining good health. ${ }^{1}$ Even the government of different countries have been working to formalize national nutrition monitoring system and there are new labelling laws for foods regarding fat and salt content. ${ }^{2,3}$ With so much focus on healthier foods and more nutritional food choices, dietary counselling and nutritional education relevant to oral health have become an important component of dental education. In fact 1987 guidelines for accreditation of dental schools by ADA requires that "the graduate must be competent to provide dietary counselling and nutritional education relevant to oral health. ${ }^{4}$ Study of diet and nutrition is also a mandatory part of curriculum in Indian dental schools. ${ }^{5}$

With nutritional issues in the spot light, it seems a good time to evaluate how orthodontic treatment affects a patient's diet. Orthodontic treatment creates physical, physiologic and emotional stresses that increase the nutrient mobilization and utilization thus raising the nutritional requirements of the person. This along with the fact that the nutritional needs of adolescents (the age of a typical orthodontic patient) is already stressed by growth and development as well as the emotional stress of puberty, maintenance of a well-balanced diet is of great importance. Fixed orthodontic treatment (braces in common language) typically lasts for around 1/1/2 to 3 years and during this duration certain dietary restrictions and modifications are advised. Typically the orthodontist often advise their patients to eat soft food during treatment to avoid pressure sensitivity but very few give clear cut instructions or provide diet charts. In absence of these, patients generally switch over to convenient easy to eat food, without any special attention to the nutrient values of the consumed food.

The literature suggests that orthodontic patient's nutritional status can affect the reaction of the tissues to orthodontic forces. ${ }^{6}$ Ascorbic acid deficiency for example is thought to slow down orthodontic tooth movement by decreasing the body's ability to heal. ${ }^{6,7}$ Less than adequate levels of ascorbic acid hinder the breakdown and reformation of collagen which is necessary for tooth movement. ${ }^{9,10}$ About $17-72 \%$ of orthodontic patients have less than optimal levels of ascorbic acid. ${ }^{10,11}$ Retention may also be affected by ascorbic acid levels as shown by a study in which guinea pigs with deficiency of ascorbic acid experienced more rapid relapse of malocclusion after treatment than non-deficient ones. ${ }^{8}$ The involvement of certain nutrients in orthodontics has been looked at in the past, but the diet as a whole has not been evaluated Orthodontists often advise their patients to eat soft foods during treatment to accommodate pressure sensitivity experienced with tooth movement however there is little literature on how orthodontic treatment affects a patient's diet and even little reports on clear cut diet guidelines for orthodontic 
patients. It was found that in the absence of proper nutritional guidelines and clear cut instructions, a nutritious balanced diet is the last thing on the patients mind in the initial 3-4 days of orthodontic adjustments especially when they think that with the braces they have very limited food choices.

\section{Braces Friendly Balanced Diet:-} Cereals (Carbohydrates):-

This group should provide $1 / 4$ th of our total energy requirements. The forms in which cereals are generally consumed in a typical Indian diet consist of chapattis, rice and bread. They are generally an easy food groups for braces wearers because most grain products are very soft and easily chewed. In cases of discomfort dunking/mashing chapattis in curries and dals ensure that you don't miss out on two most vital components of a balanced diet - carbohydrates and proteins.

\section{Milk and milk products:-}

Dairy products should comprise about $1 / 4$ th of the total dietary requirements. Strong bones and teeth rely on a diet that is rich in calcium. Dairy products provide us with calcium, vitamin D, potassium and even protein. Dairy products are an excellent choice for braces wearers because most dairy products are soft and require very little chewing. Milk, milk shakes, yogurt (curd) and cottage cheese are commonly used milk products in Indian diets and its consumption by patients should be encouraged.

\section{Vegetables:-}

Vegetables again comprise about $1 / 4$ the of the total dietary requirements. Vegetables provide us with vitamins and minerals that are essential for growing bodies. Most Indian diets consume vegetables in the cooked form, so they don't provide much of the problem for braces wearers. They can be meshed up further for increased comfort. Raw vegetables or salads can be grated or cut into bite sized pieces.

\section{Fruits:-}

Fruit is an essential part of a healthy diet but eating it with braces can be quite challenging. Hard fruits like apple, unripe pears and peaches can be very difficult to bite into because of the brackets that are on the teeth. After a wire change even the softest food can be a nightmare. For 3-4 days after an orthodontic appointment, choose citrus juicy fruits such as oranges and berries. Hard fruits can be cut bite sized pieces so they can be chewed with the back teeth. If nothing else works fruit juice is always a healthy easy option.

Frequently it is uncomfortable to bite or chew something very cold with all that metal around the teeth. Having eatables at room temperature helps.

\section{Nuts and Seeds:-}

Carefully selecting the choices from this vegetarian group will help keep the braces secure. Nuts and seeds are very hard and they are very small - two challenging aspects for braces wearers. During the duration of active orthodontic treatment select nut spreads or coarsely grind your favourite nuts and seed.

Meat:- Meat poses a problem for braces wearers because it is fibrous, making it hard to chew. Avoid eating meat right from the bone. Tofu or cottage cheese provides a safe alternative to meat as a source of protein. Select, lean, tender cuts of meat and cut them into bite size pieces before you eat it.

\section{Foods to be avoided:-}

- Gum - sugarless or otherwise

- Sticky foods - toffees, candies etc

- Hard food - nuts (unless grinded), popcorn, corn on the cob, pizza crusts, ice, cookies

To optimize patient's physiologic response to orthodontic treatment, it may be beneficial to provide dietary guidance to orthodontic patients in choosing soft food diet. This includes obtaining nutrition history, evaluating the diet, educating the patient about diet components important for oral health, motivating the patient to improve diet and follow up to support patient's effort to change food behaviours.

Patient with braces who prefer or switch over to convenience foods such as cakes, pastries, ice creams and cookies which are high in simple sugars and fats should be advised regarding the value of fruits, vegetables, grains and 
cereals in their regular diet. Nutrition goals for the orthodontic patient should be to eat a variety of foods including protein sources, dairy food, fruits, vegetables and cereals and to limit salt, fat and sugar intake.

Compliance with dietary advice is more likely if follow-up is provided. Dietary progress should be discussed at further appointments. Nutrition care should be an integral part of orthodontic care.

\section{Discussion:-}

Sean Beattie et al $^{12}$ suggested that simulating effects of daily diet and patient elastic band change compliance on orthodontic latex, Polymeric elastic bands provide one of the bases for orthodontic movement of teeth. Compared with heavy-force application, light-force application at the proper rates provides for rapid tooth movement with least patient discomfort and minimal mobility during orthodontic therapy. ${ }^{13}$ Elastic bands provide forces of these magnitudes and can be used to provide forces to augment or supplement those provided by the arch wire.

In the mouth, elastics experience constant force expression, with considerable force degradation through the first day of use,$^{14}$ most of it being in the first hour of use. ${ }^{15}$ Lumen size influences force degradation, with smaller sizes needing to be renewed more often to maintain planned force application. ${ }^{16}$ In attempts to mimic various oral environments, some studies have investigated the effects of simulated saliva environments, ${ }^{17} \mathrm{pH},{ }^{18}$ and thermocycling ${ }^{19}$ on force degradation. Various artificial saliva's have been proposed, with the simplest formulation being $0.09 \%$ aqueous sodium chloride, commonly used in simulated intraoral environment studies ${ }^{20}$ Generally, the data demonstrated significant relaxation of force once elastics were exposed to experimental conditions. Mechanical degradation effects are thought to be the primary cause for degradation of orthodontic elastic bands during clinical use. ${ }^{21}$ However, leachable moieties have been isolated from some orthodontic elastic bands, and their increasing quantities in solution coincided with force degradation over time. ${ }^{22}$ Although the degradation of orthodontic elastic materials has been studied, most of the experiments have been conducted in artificial saliva or air. Only the few aforementioned studies have assessed more aggressive environments, which simulated sub-plaque conditions and thermal challenges. In contrast, the effects of food-simulating oral environments on dental polymeric restorative materials have been studied. Various forms of degradation of polymeric restorative materials have been found to be enhanced when the restorative materials are subjected to ethanol / water, ${ }^{23,24}$ ethanol / artificial saliva, ${ }^{25}$ lactic acid, citric acid, heptane, and alcohol / water ${ }^{26}$ as simulated foods. Coffee, food dyes, vinegar, erythrosin, ${ }^{27}$ whiskey, Coca-Cola, and orange .

Gokhan Oncag et $\mathrm{al}^{28}$ stated that study investigated the effects of acidic soft drinks on the resistance of metal brackets to shear forces in vitro and in vivo. And found that there was no statistical difference in debonding resistance was found between the in vivo and in vitro groups. Areas of defect due to erosion were observed on the enamel surface around the brackets in both the in vitro and in vivo groups. Acidic soft drinks such as Coca-Cola and Sprite have a negative effect on bracket retention against shearing forces and enamel erosion.

Yasuhiro et $\mathrm{al}^{29}$, investigated changes in the bony microstructure of the upper and lower alveolar bone during masticatory loading induced by soft diet feeding in growing rats. Results suggest that alveolar osteopenia is more extensive in the mandible than the maxilla in rats that experience low masticatory loading during growth.

\section{Conclusion:-}

Nutrition is an important factor, influencing the general health and tissue tolerance of orthodontic patients at many levels. While orthodontists will rarely see frank manifestations of nutritional deficiencies, it should be recognized that suboptimal levels of certain nutrients are common and have an effect on the biologic responses of the tissues influenced by orthodontic treatment.

To optimize patient's physiologic response to orthodontic treatment, it may be beneficial to provide dietary guidance to orthodontic patients in choosing soft food diets. This includes obtaining nutrition history, evaluating the diet, educating the patient about diet components important for oral health, motivating the patient to improve diet and follow up to support patient's effort to change food behaviours. Patient with braces who prefer or switch over to convenience foods such as cakes, pastries, ice creams and cookies, which are high in simple sugars and fats, should be advised regarding the value of fruits, vegetables, grains, and cereals in their regular diet. Therefore Nutrition goals for the orthodontic patient should be to eat a balanced and healthy diet. 


\section{Bibliography:-}

1. R Sharma, S Mittal, A Singla, M Virdi. Nutritional Guidelines for Orthodontic Patients. The Internet Journal of Nutrition and Wellness. 2009 Volume 10 Number 2.

2. Yetley EA, Beloian AM, Lewis CJ. Dietary methodologies for food and nutrition monitoring. Vital Health Stat 4 1992;27:58-67.

3. Prevention of food Adulteration, Ministry of Health \& Family welfare Gazette of India [GSR No. 664(E)], 2008

4. American Dental Association. Procedures for evaluation requirements and guidelines for dental education programs. Chicago: American Dental Association, 1987.

5. MDS Course Regulation 2007, Dental council of India, Ministry of Health \& Family welfare, Government of India.

6. Hickory W, Nanda R. Nutritional considerations in orthodontics. Dent Clin North Am 1981;25:195-201.

7. Litton SF. Orthodontic tooth movement during an ascorbic acid deficiency. Am J Orthod 1974;65:290-302.

8. McCanlies JM, Alexander CM, Robnett JH, Magness WB. Effect of vitamin C on the mobility and stability of guinea pig incisors under the influence of orthodontic force. Angle Orthod 1961;31:257-63.

9. Navia JM, Menaker L. Nutritional implications in wound healing. Dent Clin North Am 1976;20:549-68.

10. Cheraskin E, Ringsdorf WM Jr. Biology of the orthodontic patient: I, plasma ascorbic acid levels. Angle Orthod 1969;39:137-8.

11. Cheraskin E, Ringsdorf WM Jr. Biology of the orthodontic patient: II, lingual vitamin C test scores. Angle Orthod 1969;39:324-5.40.

12. Sean Beattie, BSa; Peter Monaghan, DDS, PhDb An In Vitro Study Simulating Effects of Daily Diet and Patient Elastic Band Change Compliance on Orthodontic Latex Elastics Angle Orthodontist, Vol 74, No 2, 2004

13. Van Leeuwen EJ, Maltha JC, Kuijpers-Jagtman AM. Tooth movement with light continuous and discontinuous forces in beagle dogs. Eur J Oral Sci. 1999;107:468-474.

14. Bertran Von C. The forces of the rubber bands. [Die Kra"fte Der Orthodontischen Gummiligatur.] Fortschr Orthod. 1931;1:605.

15. Kanchana P, Godfrey K. Calibration of force extension and force degradation characteristics of orthodontic latex elastics. Am J Orthod Dentofacial Orthop. 2000;118:280-287.

16. Chaconas SJ, Caputo AA, Belting CW. Force degradation of orthodontic elastics. CDA J. 1978;6:58-61.

17. Andreasen GF, Bishara SE. Comparison of time related forces between plastic alastiks and latex elastics. Angle Orthod. 1970;40:319-328.

18. 18 . Ferriter JP, Meyer CE, Lorton L. The effects of hydrogen ion concentration on the force degradation rate of orthodontic polyurethane chain elastics. Am J Orthod Dentofacial Orthop. 1990;98:404-410.

19. De Genova DC, McInnes-Ledoux P, Weinberg R, Shaye R. Force degradation of orthodontic elastomeric chains - a product comparison study. Am J Orthod. 1985;87:377-384.

20. Stevenson JS, Kusy RP. Force application and decay characteristics of untreated and treated polyurethane elastomeric chains. Angle Orthod. 1994;64:455-464.

21. Huget EF, Patrick KS, Nunez LJ. Observations on the elastic behavior of a synthetic orthodontic elastomer. J Dent Res. 1990;69:496-501.

22. Sun D, Monaghan P, Brantley WA, Johnston WM. Potentiodynamic polarization study of the in vitro corrosion behavior of 3 high-palladium alloys and a gold-palladium alloy in 5 media. J Prosthet Dent. 2002;87:86-93.

23. McKinney JE, Wu W. Chemical softening and wear of dental composites. J Dent Res. 1985;64:1326-1331.

24. Ferracane JL, Marker VA. Solvent degradation and reduced fracture toughness in aged composites. J Dent Res. 1992;71:13-19.

25. Lee SY, Greener EH, Mueller HJ. Effect of food and oral simulating fluids on structure of adhesive composite systems. J Dent.1995;23:27-35.

26. Yap AU, Low JS, Ong LF. Effect of food-simulating liquids on surface characteristics of composite and polyacid-modified composite restoratives. Oper Dent. 2000;25:170-176.

27. Dietschi D, Campanile G, Holtz J, Meyer JM. Comparison of the color stability of ten new-generation composites: an in vitro study. Dent Mater. 1994;10:353-362.

28. Gokhan Oncag, DDS, PhDa; Ali Vehbi Tuncer, DDS, PhDb; Yahya Serif Tosun, DDS, PhDc : Acidic Soft Drinks Effects on the Shear Bond Strength of Orthodontic Brackets and a Scanning Electron Microscopy Evaluation of the Enamel(Angle Orthod 2005;75:247-253.)

29. Yasuhiro Shimizu Takayoshi Ishida a, Jun Hosomichi, Sawa Kaneko Kasumi Hatano, Takashi Ono Soft diet causes greater alveolar osteopenia in the mandible than in the maxilla archives of oral 1 biology 58 (2013) 907 911. 
30. 31. Reiko Sakashita, Naohiko Inoue, Qifeng Pan, and Hong Diet and Discrepancy Between Tooth and Jaw Size in the Yin-Shang Period of China American Journal of Physical Anthropology 103:497-505 (1997).

31. 32. Simon A. Mays Loss of Molar Occlusion and Mandibular Morphology in Adults in an Ancient Human Population Consuming a Coarse Diet American Journal of Physical Anthropology 152:383-392 (2013). 